\title{
Unemployment, capital accumulation and labour market institutions in the Great Recession*
}

\author{
Engelbert Stockhammer, Alexander Guschanski and Karsten Köhler \\ Kingston University, Kingston upon Thames, UK
}

\begin{abstract}
This paper restates the post-Keynesian view of unemployment within a NAIRU framework. In the short run, the private effective labour demand need not be downward sloping because of debt deflation and wage-led demand regimes. In the medium run, the NAIRU will be endogenous because of the social norm character of wage setting and the supply-side effects of capital accumulation. Capital investment rather than labour market institutions is the crucial variable that explains changes in unemployment performance. We provide econometric evidence that the post-Keynesian view holds up well in the recession following the crisis of 2008.
\end{abstract}

Keywords: unemployment, NAIRU, post-Keynesian economics, panel analysis

JEL codes: E12, E24, E25

\section{INTRODUCTION}

The financial crisis beginning in August 2007 has led to the deepest recession in two generations. It is remarkable how little has changed within the economics profession in reaction to this. While there is arguably some rethinking as regards the role and efficiency of financial markets, there is little questioning of orthodox wisdom as regards macroeconomics in general and the labour market in particular. The standard New Keynesian (NK) NAIRU theory regards medium-term unemployment as being determined by labour market institutions (LMI). The global financial and economic crisis has illustrated, first, that big changes in unemployment are driven by demand shocks rather than changes in LMI; and, second, that elevated levels of unemployment persist for a long time. In modern language, the equilibrium unemployment seems to be path dependent.

In this paper we will reinstate the post-Keynesian (PK) view that in the short as well as in the medium term, the labour market is dominated by demand on the goods market, in particular by capital accumulation. We will set our argument within a NAIRU model to ensure comparability with modern mainstream economics.

The paper makes three central claims. First, at any point in time there is a well-defined short-term NAIRU, but it need not be an attractor for actual unemployment. Keynesian theory distinguishes between the notional, technologically given labour demand curve and effective labour demand. Effective labour demand need not be downward sloping because of debt-deflation effects and/or because aggregate demand may be wage led. Second, there is a broad case for unemployment hysteresis based on social norms in wage bargaining and

* This paper is based on a lecture delivered at the FMM conference, Berlin, Germany, 2013 and builds on Stockhammer (2011) and Stockhammer/Klär (2011). 
the supply-side effects of capital accumulation. The NAIRU will thus be endogenous in the medium term and demand shocks can have long-lasting effects on unemployment. Third, investment expenditures are the single most important determinant of unemployment performance because they are prone to wide fluctuations and determine the capital stock. This assertion is in sharp contrast to the mainstream NAIRU story, which regards LMI as the main driving force of unemployment. The contribution of the present paper is to assess the empirical validity of these claims for the aftermath of the financial crisis. We present an econometric estimation of the NAIRU model accounting for the effects of LMI, capital accumulation and housing bubbles for a panel of twelve OECD countries for the period 2007-2011.

The paper is structured as follows. Section 2 presents a general NAIRU model and highlights that the mainstream NAIRU story is only one specific interpretation of the NAIRU model. Section 3 argues that the effective labour demand curve need not be downward sloping (with respect to the real wage) and that the $\mathrm{AD}$-curve will in general not be downward sloping (with respect to inflation), except in so far as this is caused by monetary policy. Section 4 maintains that unemployment hysteresis is ubiquitous due to social norms in wages and the fact that capital investment has demand as well as supply-side effects. Section 5 surveys the empirical literature on the determinants of unemployment. Section 6 presents econometric evidence for the relative explanatory power of capital accumulation and LMI during the Great Recession. Finally, Section 7 concludes.

\section{THE NAIRU MODEL AND THE NAIRU STORY}

The NAIRU model is a rather general framework that can accommodate different theories. At the core it posits a short-run trade-off between unemployment and inflation that is, a short-run Phillips curve. Equilibrium can, in principle, be stable or unstable, according to the adjustment in the goods market. And the NAIRU can be endogenous or exogenous; Stockhammer (2008) shows that, depending on the assumptions about the demand function and about the endogeneity or exogeneity of the NAIRU, the NAIRU model is consistent with a Monetarist, NK, PK or Marxist interpretation.

The general NAIRU model is based on a bargaining view of the labour market. Wage contracts are not the result of a market clearing process but are negotiated by labour unions and large firms. The bargaining power of labour positively depends on the level of employment. The model presupposes that both sides have market power - otherwise there would be nothing to bargain about. There will only be one level of employment at which the expected real wage (given inflation expectations) is consistent with the real wage implied by the prices set by (oligopolistic) firms (given their expectations about input price inflation and wage inflation). In other words, there will only be one level of employment at which the income claims of labour and capital are consistent. Inflation in the NAIRU model is the result of a distributional conflict and unemployment is determined by effective demand in the goods market (in the short run). This is the Keynesian feature of the model.

Actual unemployment will only converge to the NAIRU if the goods market adjustment is standard. If the $\mathrm{AD}$-curve is downward sloping, then the labour market equilibrium is self-adjusting. When demand pushes unemployment below the NAIRU, there is an increase in inflation, which in turn decreases demand. Consequently unemployment will increase and actual unemployment converges to the NAIRU.

Any claim that unemployment is determined by the NAIRU in the medium and long term requires the additional condition that the NAIRU itself does not change during the adjustment period. 
The NAIRU model has become the dominant framework for the macroeconomic analysis of unemployment, as reflected in textbooks like Blanchard (2006) or Carlin/Soskice (2005). Following influential work by Layard et al. (1991) the NAIRU theory has become associated with the argument that actual unemployment is over longer periods primarily determined by LMI (for example, IMF 2003, Nickell et al. 2005). We refer to this as the NAIRU story and argue that it is a specific (NK) interpretation of the NAIRU model.

The NAIRU story - that is, the assertion that actual unemployment is primarily determined by changes in labour market institutions - is but one particular interpretation of the NAIRU model that assumes a standard negative effect of inflation on demand and the exogeneity of unemployment with respect to its own history. The NAIRU story has become the dominant view on unemployment and has informed policy recommendations of labour market deregulation as the key means to change medium-term unemployment (OECD 1994; 2006; European Commission 2003; IMF 2003). We will thus use the terms 'NAIRU story' and 'mainstream view' synonymously. The model, however, can also be given a PK interpretation.

\section{THE SHORT RUN: THE NAIRU AS A WEAK ATTRACTOR}

The first key difference between the PK interpretation and the NK view is that the goods market adjustment will be weak or may not lead towards the labour market equilibrium at all. The NAIRU will thus at best be a weak attractor. In mainstream theory there are two explanations why the AD-curve is downward sloping. The first is based on the Monetarist assumption that the money supply is exogenous. An increase in the rate of inflation will decrease the real money supply and consequently increase interest rates, which will depress aggregate demand. Some seminal papers on the NAIRU (for example, Nickell 1998) use this assumption.

The second, modern, answer to the question of why the AD-curve is downward sloping is the central bank's policy reaction. Most central banks increase interest rates in response to (or in anticipation of) inflation. This reaction could be part of a strict inflation targeting regime or part of a more flexible Taylor Rule. Indeed, post-Keynesians have argued that the interest rate (rather than the money supply) has been the prime monetary policy well before the recent popularity of the Taylor Rule (Kaldor 1970; 1982; King 2002, ch. 8).

The argument that the central bank creates the negative reaction of aggregate demand to an increase in inflation has important implications for the interpretation of the NAIRU. First, it highlights that the adjustment of actual unemployment to the NAIRU is essentially due to a policy reaction, not an economic automatism. Hence, the market system in this view is not self-adjusting. Second, there are limitations to the effectiveness of monetary policy. Once inflation and interest get close to zero, it will be impossible for the central bank to lower real interest rates (by conventional means). This is the Zero Lower Bound for nominal interest rates that features prominently in many recent New Keynesian models (de Long/Summers 2012; Eggertson/Krugman 2012).

For the monetary policy rule to equilibrate the economy, the private sector reaction to a change in interest rates has to be sufficiently strong. Keynes had pointed out that there are several situations where this may not be the case: in times of financial crisis the demand for money can become perfectly elastic with respect to the interest rate (a liquidity trap), risk premia may surge, breaking the usual link between the central bank rate and loan rates, banks may hoard liquidity and not extend credit (credit rationing) or investors 
may not react to changes in interest rates because they are worried about the future (an investment trap).

Furthermore, the private sector adjustment to a wage-price spiral may be perverse. Fisher (1933) has argued that (unexpected) deflation increases the real debt burden and may have negative demand effects. As a consequence, different monetary policy rules may result in different NAIRUs.

A second, closely related question is whether the labour demand curve is downward sloping: ${ }^{1}$ Keynesians have established that there is a difference between notional labour demand and effective labour demand (for example, Lavoie 2003). If one is willing to assume an aggregate production function, the notional labour demand curve is technologically determined by the first order condition of a profit maximising firm. It assumes that there are no demand constraints for the firm. The effective labour demand is derived from aggregate demand, given changes in (real or nominal) wages, and incorporates how $\mathrm{AD}$ will change in reaction to changes in wages.

In a recession, firms typically have spare capacity, which implies that the economy is off the production function and off the (notional) labour demand curve. In a world with excess capacity, a wage cut will have ambiguous effects on aggregate demand. Other things being equal, one would expect a redistribution of income from labour to capital to have a negative effect of consumption demand (as wage earners are likely to have a higher consumption propensity than earners of profit income), a positive effect on investment (which depends positively on retained earnings) and a positive effect on net exports (assuming that the decrease in the wage share comes with a nominal wage decrease that feeds into domestic prices and improves competitiveness). A priori the total effect of a change in the wage share is thus indeterminate and can be either positive or negative (Bhaduri/Marglin 1990). Most of the empirical studies find that for large economies the demand regime is wage led (Naastepad/ Storm 2007; Hein/Vogel 2008; Onaran/Galanis 2012). For example, Stockhammer et al. (2009) find that for the Euro (12) zone, a 1 percentage point increase in the wage share leads to an increase in consumption by 0.4 per cent (of GDP), a decline of investment by 0.1 per cent and a decline of net exports by 0.1 per cent, with the net effect being +0.2 per cent - that is, private excess demand in the euro area turns out to be wage led. The effective labour demand may thus be upward sloping. ${ }^{2}$

In short, the $\mathrm{AD}$ curve is likely to be downward sloping in normal times because of central bank reaction, but it need not in times of financial turmoil, when monetary policy becomes ineffective, and once the economy is close to (or in) deflation. The goods market adjustment to disequilibria on the labour market critically depends on policy reactions and their effectiveness.

\section{THE MEDIUM TERM: UNEMPLOYMENT HYSTERESIS AND ENDOGENEITY OF THE NAIRU}

In the medium term, the crucial question is whether the NAIRU is affected by actual unemployment. In the NK literature, unemployment persistence is often used to describe

1. There have been several microeconomic arguments that the labour demand curve need not be downward sloping (Card/Krueger 1994; Manning 1995), but our concern here is a macroeconomic one. 2. There is a large literature trying to empirically identify labour demand curves. However, national accounting identities will give rise to spurious negative slopes. Anyadike-Danes/Godley (1989) demonstrated that estimated labour demand functions will generate negative slopes based on data that were simulated assuming fixed coefficient technology and mark-up pricing (see also Felipe/McCombie 2009). 
situations where actual unemployment depends on past unemployment, while the NAIRU is independent of past unemployment. Unemployment hysteresis is used for situations where the NAIRU itself reacts to changes in actual unemployment. The standard NAIRU literature treats unemployment persistence as a matter of great practical importance but little theoretical significance, whereas unemployment hysteresis is regarded as a special case (Nickell 1998). In contrast, the PK view argues that unemployment hysteresis or NAIRU endogeneity will be a widespread and pervasive phenomenon.

In the NK analysis of unemployment persistence, the long-term unemployed have a different effect on wages than the short-term unemployed. When people stay unemployed for an extended period, they start losing their skills or potential employers start discriminating against them. Also, labour unions may not give full weight to the (long-term) unemployed when bargaining. There will be a short-term NAIRU that depends on past unemployment and differs from the long-term NAIRU. Nickell (1998) shows that, as long as long-term unemployment has some effect on wages, the short-term NAIRU will eventually converge to the (long-term) NAIRU.

In the PK view, the case for NAIRU endogeneity is much broader (Skott 2005; Stockhammer 2008). First, if workers' evaluation of wages follows social norms - for example, a comparison with other people's wages or with their own wage in the past - then any actual wage level can become accepted as 'normal', if it persists long enough. ${ }^{3}$ When actual unemployment deviates from the NAIRU, the actual wage will also deviate from the equilibrium wage. Our case for unemployment hysteresis rests on the endogeneity of wage claims rather than on the disciplining effect (or lack thereof) of the long-term unemployed.

Figures 1 and 2 illustrate the difference between the NK and the PK argument. To simplify the discussion, we will assume a standard goods market adjustment in both cases and that actual wages are determined by the price setting curve (PSC). Figure 1 presents the persistence due to insufficient wage pressure by the long-term unemployed. There is a NAIRU equilibrium $u_{N}$ and a demand shock that pushes the economy to $T_{1}$. Actual unemployment is at level $u_{1}$ and actual real wages are at $W / P_{1}$. Because of high

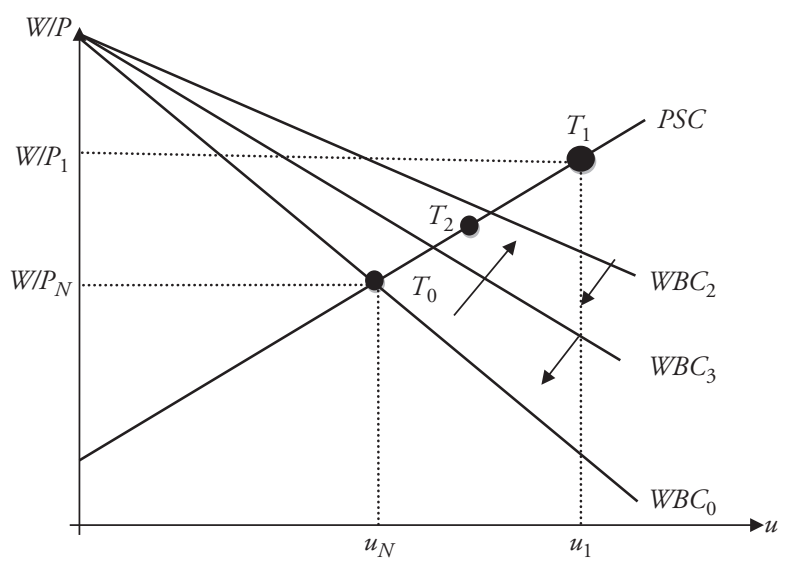

Figure 1 Standard unemployment persistence

3. Behavioural economics has demonstrated that perceived fairness of wages may impact on labour market outcomes (see, for example, Fehr et al. 1998). 


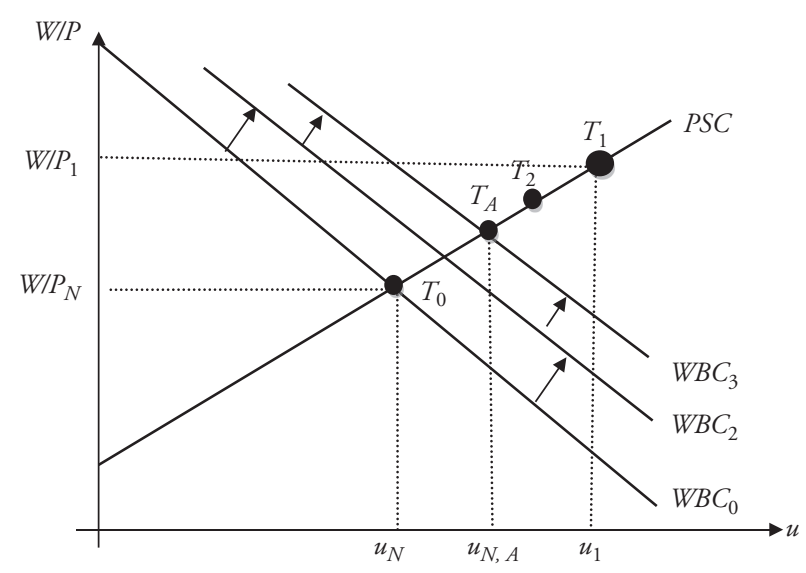

Figure 2 NAIRU endogeneity due to social wage norms

unemployment in period 1, long-term unemployment increases and in the next period the wage bargaining curve $\left(W B C_{0}\right)$ will rotate outwards to $W B C_{2}$. This curve has the same intercept, but a different slope, which represents the fact that the long-term unemployed do exercise only limited pressure on wages. As actual wages are above workers' wage aspirations at the given level of unemployment, inflation will be declining and (assuming standard goods market adjustment) output and employment will increase. As the number of long-term unemployed decreases, the slope of the WBC becomes steeper. The WBC will thus rotate inwards to $W B C_{3}$ and eventually will approach $W B C_{0}$, which is determined only by labour market institutions.

The PK wage norm argument is illustrated in Figure 2. As a result of the demand shock, not only will actual employment deviate from the NAIRU, but the actual wage will also deviate from the wage at the NAIRU $(W I P)_{N}$. We assume that real wages are given by the PSC, thus there is an increase in real wages. If the demand shock lasts long enough for workers to perceive the new wage level as normal, the WBC will shift parallel. The extent to which the WBC shifts will depend on how long the economy remains at $T_{1}$. The longer the economy stays off equilibrium, the more the wage norms will shift. Eventually the economy will settle at some point, $T_{A}$, between the original equilibrium and $T_{1}$, depending on the depth and duration of the shock and the adjustment speed of wage norms. The NAIRU has changed to $u_{N, A}$. There are two key differences from Figure 1. First, there has been a shift of the curve rather than a rotation, because the change is due to changing wage norms rather than to the (lack of) wage pressure due to the long-term unemployed. Second, the WBC is now shifting towards the actual wage level, rather than rotating towards the original curve. This is because, with each round of adjustment, wage norms will change towards the actual level, whereas the number of long-term unemployed is gradually decreasing.

A second reason why the NAIRU will be endogenous is that investment expenditure has demand-side as well as supply-side effects. The demand-side effects are the familiar multiplier effects. The supply-side effect is that changes in investment expenditures will affect the capital stock, which has two effects on the NAIRU. First, if one is willing to assume standard production functions, it will affect the marginal product of labour and thus the PSC. As Rowthorn (1999) has shown, the NAIRU will depend on the capital stock unless the elasticity of substitution is exactly equal to unity - that is, unless the 
production function is Cobb-Douglas. Second, the capital stock will also affect the mark-up because, for a given level of output, a change in the capital stock will change capacity utilisation which will affect the price-setting power of firms (Rowthorn 1977).

Thus, the NAIRU is endogenous, at least if shocks are strong enough and enduring. Indeed the empirical literature often concludes that there is unemployment hysteresis. ${ }^{4}$ Several surveys find evidence, especially for European countries, for a unit root in the unemployment rate (Røed 1997; León-Ledesma 2002). Stanley (2004) performs a metaregression analysis of 24 publications with 99 regressions on the determinants of unemployment and finds a persistence coefficient close to unity, which indicates full hysteresis. Remarkably, the OECD (2009) is concerned about NAIRU endogeneity: it has revised its NAIRU estimates upward (and its estimates for potential output downward) in response to the deep recession of 2008-2009. If the NAIRU were exogenous, there would be no reason for the NAIRU to change.

\section{THE EMPIRICAL LITERATURE ON LMI, CAPITAL ACCUMULATION AND UNEMPLOYMENT}

While the Keynesian view regards capital accumulation as the key variable determining aggregate demand, the mainstream view argues that unemployment is, beyond shortterm fluctuations, effectively determined by LMI. However, the strong policy conclusions of orthodox economists who call for labour market deregulation are not unanimously backed by their empirical findings. IMF (2003) estimates a panel of 20 OECD countries and finds significant effects for employment protection, union density, the tax wedge, the interest rate and productivity shocks. Nickell et al. (2005) estimate a non-linear least square panel with country-specific time trends and find significant effects of the unemployment benefit replacement ratio and (the change in) union density, some interactions, labour demand shocks and import price shocks. Both find a very high degree of unemployment persistence. More recently, Flaig/Rottman (2013) estimate a panel of 19 OECD countries from 1960 to 2000 and find statistically significant effects of employment protection, benefit replacement rate and the tax wedge. The centralisation of the wage bargaining process significantly reduces unemployment. They also report that coefficients vary substantially across countries.

However, many other studies find mixed, weak, or no effects of LMI. Blanchard/Wolfers (2000) present a panel investigation for 20 OECD countries and highlight the interaction of macroeconomic shocks and institutions. They conclude: 'While labor market institutions can potentially explain cross country differences today, they do not appear able to explain the general evolution of unemployment over time' (ibid.: 2). Baker et al. (2005) attempt to replicate previous findings by means of a panel with 5-year averages; they conclude that there is 'no meaningful relationship between [the] OECD measure of labor market deregulation and shifts in the NAIRU' (ibid.: 107). Bassanini/Duval (2006) use a dynamic panel analysis of 21 OECD countries over the 1982-2003 period and find that benefit generosity and the tax wedge are the only classic LMI to have a significant effect. Baccaro/Rei (2007) offer an extensive attempt to replicate previous estimations employing various econometric estimation techniques and find significant effects only of union density among the labour market institutions. Two recent studies follow

4. Our theoretical concept of hysteresis is defined as (medium-term) endogeneity of the NAIRU. Empirical tests of the unemployment hysteresis usually test for a unit root in unemployment, which is a stronger condition than implied by our argument. 
Blanchard/Wolfers's (2000) accounting for LMI and macro shocks. The European Commission (2012) investigates the impact of LMI and macro shocks on the NAIRU using a panel analysis of 13 EU countries over the 1985-2009 period. It confirms the strong impact of LMI, but also notes the importance of demand factors such as the interest rate and volatility of employment in the construction sector due to housing bubbles. However, these factors are not clearly articulated in the theoretical framework. Avdagic/Salardi (2013) present a panel regression of 32 OECD countries (1980-2009) and of 10 CEE countries (1990-2009). They find a significant effect only for wage bargaining coordination which reduces unemployment. Union density and benefit generosity are significant in some specifications, but do not survive the robustness tests. Notably, none of these studies includes capital accumulation as a potential determinant of the NAIRU - that is, none of these studies allows for a Keynesian null hypothesis.

In their policy reports, the OECD and the ECB discuss labour market performance in the aftermath of the Great Recession in a more pragmatic way, without adhering strictly to the NK NAIRU model. At an early stage of the crisis, the OECD $(2010 ; 2011)$ discusses risks and policy implications resulting from persisting unemployment and the danger of a jobless recovery. Although empirical data do not indicate extensive withdrawal from the labour force until now, the report worries that this might happen in the future. A variety of labour market reforms such as activation policies, reduction of benefit replacement ratios and restricting early retirement is suggested in order to reduce unemployment persistence by increasing the labour force and labour market flexibility. This corresponds to the NK concept of persistence, although the authors do not explicitly refer to any theoretical framework. While the report does emphasise the role of aggregate demand management, the policy suggestions are focused on stimulating demand through removing market barriers - especially regarding the fiscal imbalances in most OECD countries. ECB (2012) reports that employment in countries with a strong pre-crisis credit boom and current account deficits was hit especially hard by the recession. Employment losses were above average in the manufacturing and construction sector. Unemployment persistence due to skill mismatch is recognised. However, in its policy conclusions the ECB highlights only wage flexibility as the cure for unemployment. While the OECD does see some role for demand management, there is no mention of it by the ECB. Neither of them assigns any significance to capital accumulation.

The Keynesian view holds that capital accumulation is the main determinant of unemployment performance in the medium term. Econometric evidence supporting strong effects of capital accumulation has been found by a range of different methodologies, but studies notably differ in the extent to which they control for LMI - that is, to what extent they encompass the mainstream explanation. Stockhammer (2004) uses time series analysis for five countries and controls for the tax wedge, unemployment benefits and union density. Arestis et al. (2007) apply a vector error correction model for nine countries and control for unemployment benefits and strike activity. Both studies find strong effects of capital accumulation. Karanassou/Snower (1998) and Karanassou et al. (2008) estimate a system of labour demand, wage setting and labour supply curves and (controlling for a limited set of LMI) find strong effects of capital accumulation (for the UK and Scandinavian countries respectively). Rowthorn (1995) and Alexiou/Pitelis (2003) report significant effects of capital accumulation with a cross-section and panel approach respectively, but do not control for any LMI.

The most encompassing work with panel data is Stockhammer/Klär (2011), who perform a panel analysis for OECD countries controlling for the full set of LMI used in OECD (2006). They find strong capital accumulation effects, substantial effects of interest rates, but very small effects of LMI. Simulations show that the explained contributions of changes in actual capital expenditures clearly dominate the contributions of other factors. 


\section{UNEMPLOYMENT DURING THE 2008 CRISIS}

Our econometric analysis follows Stockhammer/Klär (2011), who propose a PK version of the NAIRU that encompasses standard NAIRU factors. However, we focus on the crisis period and estimate a panel for the period 2007-2011.5 Thereby, just as in other corresponding literature, homogeneity of coefficients has to be imposed across countries (Blanchard/Wolfers 2000, Baccaro/Rei 2007). The baseline regression equation takes the following form:

$$
u_{t, j}=b_{1} \Delta I N F L_{t, j}+b_{2} L M I_{t, j}+b_{3} M S_{t, j}+b_{4} A C C U_{t, j}+\epsilon_{t, j}
$$

where $u$, INFL, LMI, MS and ACCU denote unemployment, inflation, labour market institutions, macroeconomic shocks and capital accumulation respectively. This equation is a general reduced form of the NAIRU. The change in the inflation rate $(\triangle I N F L)$ is a measure of the deviation of actual unemployment from the NAIRU. This is a feature of all NAIRU models. The standard NK NAIRU model highlights the role of LMI (see, for example, Nickell 1998), whereas extended versions of the NK model include also various macro shocks (see, for example, Blanchard/Wolfers 2000). The PK version includes capital accumulation and posits that this will be the key variable, but allows for the effects of standard variables as well. $A C C U$ embodies the demand-side effect of investment, as well as the supply-side effect of the capital stock.

We include five labour market institutions, namely employment protection legislation (EPL), active labour market policies (ALMP), minimum wages ${ }^{6}$ (MW), union density (UD) and gross benefit replacement ratio (GRR). All these are wage push variables and are expected to have a positive sign, apart from ALMP which are supposed to decrease search unemployment and mismatch. The data are taken from the OECD database. The GRR annual time series is intrapolated from 2-year data. ${ }^{7}$ As macroeconomic shocks, we consider the long-term interest rate (LTI) and, following European Commission (2012), a variable measuring housing bubbles (HOUSEBUB). Data on unemployment rates, real net capital stock, real gross fixed capital formation, ${ }^{8}$ the consumer price index, employment in the construction sector, total employment and long-term real interest rates are taken from the AMECO database provided by the European Commission. ACCU is the ratio of gross fixed capital formation to the capital stock. $\triangle I N F L$ is the second derivative of the logarithm of the consumer price index. ${ }^{9}$ We follow European Commission (2012) and construct HOUSEBUB, as the deviation of the ratio of employment in the construction sector to total employment from its mean. Data availability is constrained by the availability by LMI data and HOUSEBUB. Depending on the specification, we cover 8 to 12 OECD countries.

5. Unlike Stockhammer/Klär (2011), we do not use 5-year averages to account for business cycle fluctuations because of the brevity of the chosen period.

6. Values of MW have been divided by 100 .

7. We have chained two separate time series of gross replacement rates. The first series ranging from 1961 to 2005 is based on Average Production Worker wages, whereas the second time series (2005 to 2011) is based on Average Worker wages. Further details can be found at OECD Benefits and Wages: Statistics (available at http://www.oecd.org/els/benefitsandwagesstatistics.htm).

8. Gross fixed capital formation captures the demand side of aggregate investment. The AMECO dataset does offer series for residential and non-residential investment. Future research could include these two types of investment separately.

9. Values of INFL, ACCU and HOUSEBUB have been multiplied by 100. 
The most commonly used estimation technique in our context is a fixed-effects (FE) panel estimator in levels (European Commission 2012; Avdagic/Salardi 2013; Flaig/Rottmann 2013). However, using this method, results are plagued with autocorrelation problems. Thus, like Baccaro/Rei (2007), we prefer the first difference estimator. ${ }^{10}$

Table 1 presents the results for several specifications. Specifications 1, 2, 3, 4 and 6 use first difference estimators; specification 5 employs an FE estimator. Standard errors are corrected for autocorrelation and cross-section heteroscedasticity. Specifications 1-5 are based on the sample 2007-2011; specification 6 extends the sample to 1986-2011 to confirm that our model is consistent with data before the crisis period.

Specifications 1 and 2 are versions of the standard NK NAIRU interpretation. The coefficient estimate on $\triangle I N F L$ is statistically insignificant in specifications 1 and 2 . The LMI variables perform poorly in the basic NAIRU specifications. ALMP is statistically significant in specification 1 and 2 and has a perverse sign; MW is weakly significant only in specification 1. All other LMI variables are statistically insignificant. In the short sample, long-term interest rates remain insignificant in all specifications. In specification 2, HOUSEBUB is statistically significant at the 1 per cent level. In short, our findings give little support to the standard NAIRU theory.

The PK specification 3 fares better, with ACCU being statistically significant at the 1 per cent level. A 1 per cent increase in capital accumulation would reduce unemployment by 2 percentage points. HOUSEBUB remains statistically significant at the 1 per cent level and $\triangle$ INFL at the 5 per cent level. Among the LMI, only GRR is significant at the 10 per cent level. The following specifications check the robustness of this model.

Specification 4 excludes minimum wages, which increases the sample of countries from 8 to 12 . GRR becomes insignificant, but the other coefficients don't change substantially. Specification 5 uses the FE estimator instead of the difference estimator. ACCU and HOUSEBUB remain statistically significant at the 1 per cent level and $\triangle I N F L$ at the 5 per cent level. Among the LMI variables, MW is now statistically significant at the 5 per cent level and has a negative effect on unemployment. GRR has a statistically significant positive effect at the 1 per cent level. Specification 6 extends the sample to the period 1986-2011, which confirms our results regarding the negative impact of ACCU and HOUSEBUB on unemployment. We obtain three significant LMI variables: UD, MW and ALMP. While the latter remains with a perverse sign, the positive effect of UD on unemployment is in line with previous findings (Stockhammer/Klär 2011). The MW is significant at the 10 per cent level. However, the main drivers are clearly HOUSEBUB and ACCU.

\section{CONCLUSION}

This paper has highlighted the differences between the PK and the mainstream (NK) analysis of unemployment. We have used a NAIRU framework and argued that its bargaining conception of the labour market and the fact that goods market adjustments are crucial make it consistent with PK theory. The PK approach differs from the NK one in that it highlights that the short-run adjustment relies on monetary policy, which is unlikely to be effective in times of financial crises. In the medium term, hysteresis phenomena are pervasive features of the labour market because of the social norm aspect of wages and the supply-side effects of capital accumulation. In our view, labour market performance is driven by

10. Estimating an autoregressive distributed lag model gave clear support for the difference specification. 


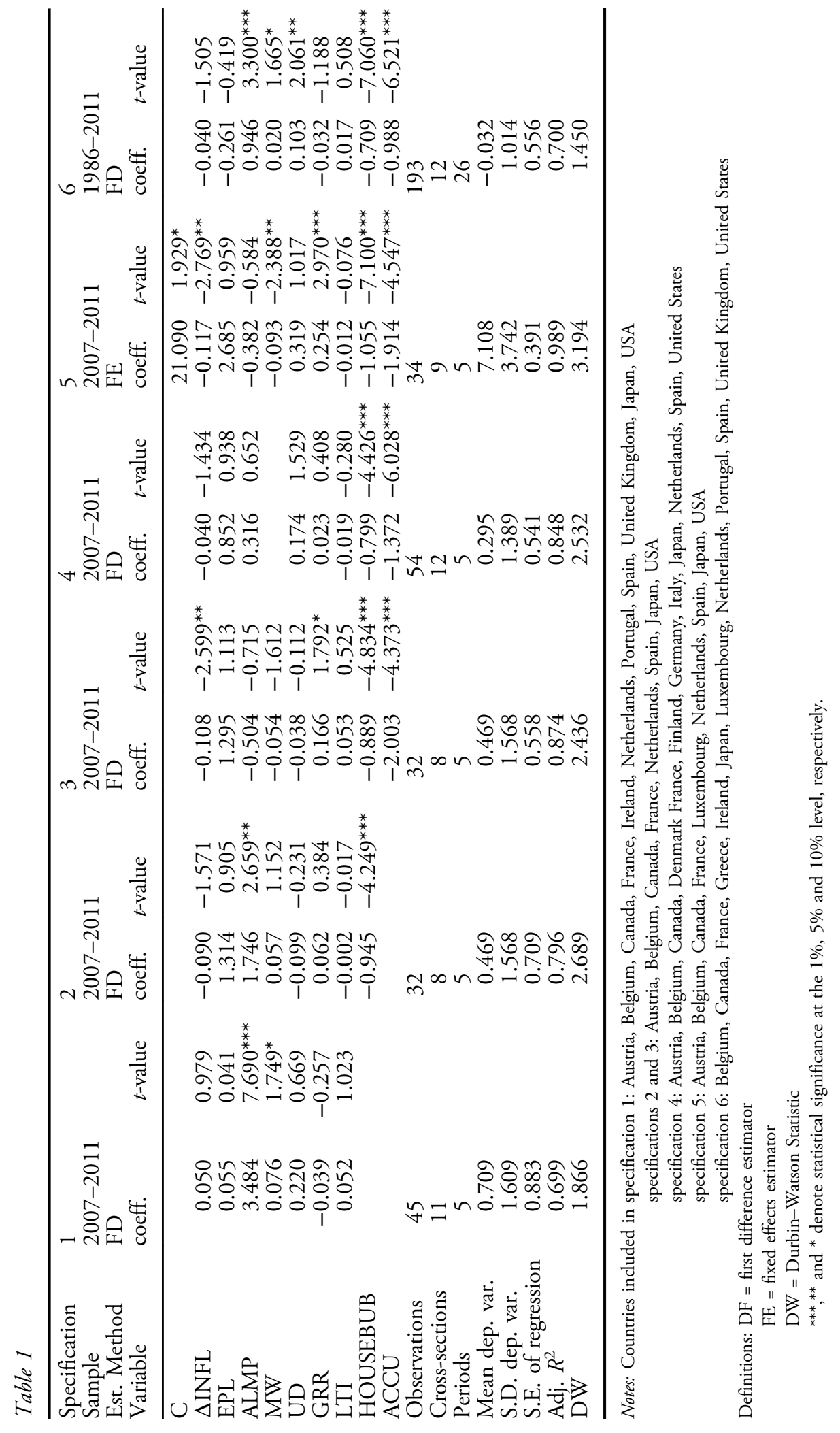


demand shocks, most importantly by investment behaviour. We have substantiated this view empirically with an econometric panel analysis of the recent crisis experience, which demonstrates that capital accumulation (as well as housing bubbles), rather than LMI, are the main drivers of unemployment performance. The PK view lends itself to a very different policy conclusion from the orthodox view. Wage flexibility may be counterproductive in a crisis and active fiscal policies are needed to stabilise employment.

\section{REFERENCES}

Alexiou, C., Pitelis, C. (2003): On capital shortages and European unemployment: a panel investigation, in: Journal of Post Keynesian Economics, 25(4), 613-640.

Anyadike-Danes, M., Godley, W. (1989): Real wages and employment: a sceptical view of some recent empirical work, in: Manchester School, 75(2), 172-187.

Arestis, P., Baddeley, M., Sawyer, M. (2007): The relationship between capital stock, unemployment and wages in nine EMU countries, in: Bulletin of Economic Research, 59(2), 125-148.

Avdagic, S., Salardi, P. (2013): Tenuous link: labour market institutions and unemployment in advanced and new market economies, in: Socio-Economic Review, 11, 739-769.

Baccaro, L., Rei, D. (2007): Institutional determinants of unemployment in OECD countries: does the deregulatory view hold water? in: International Organization, 61, 527-569.

Baker, D., Glyn, A., Howell, D., Schmitt, J. (2005): Labor market institutions and unemployment: a critical assessment of the cross-country evidence, in: Howell, D. (ed.), Fighting Unemployment. The Limits for Free Market Orthodoxy, Oxford: Oxford University Press, 72-118.

Bassanini, A., Duval, R. (2006): Employment patterns in OECD countries: reassessing the role of policies and institutions, OECD Economics Department Working Paper No. 486, Paris: OECD.

Bhaduri, A., Marglin, S. (1990): Unemployment and the real wage: the economic basis for contesting political ideologies, in: Cambridge Journal of Economics, 14, 375-393.

Blanchard, O. (2006): Macroeconomics, 4th edn, Upper Saddle River, NJ: Prentice Hall.

Blanchard, O., Wolfers, J. (2000): The role of shocks and institutions in the rise of European unemployment: the aggregate evidence, in: Economic Journal, 110, 1-33.

Carlin, W., Soskice, D. (2005): Macroeconomics: Imperfections, Institutions and Policies, Oxford: Oxford University Press.

De Long, B., Summers, L. (2012): Fiscal policy in a depressed economy, in: Brookings Papers on Economic Activity, 44(1), 33-297.

ECB (2012): Euro area labour markets and the crisis, in: ECB Monthly Bulletin, Oct 2012, 69-80.

Eggertson, G., Krugman, P. (2012): Debt, deleveraging, and the liquidity trap: a Fisher-Minsky-Koo approach, in: Quarterly Journal of Economics, 127(3), 1469-1513.

European Commission (2003): Wage flexibility and wage interdependencies, EMU, European Economy: 2003 Report, ch. 4.

European Commission (2012): Structural unemployment and its determinants in the EU countries, European Commission, Economic Papers 455, May 2012.

Fehr, E., Kirchler, E., Weichbold, A., Gächter, S. (1998): When social norms overpower competition: gift exchanges in experimental labor markets, in: Journal of Labor Economics, 16(2), 324-351.

Felipe, J., McCombie, J. (2009): Are estimates of labor demand functions mere statistical artefacts?, in: International Review of Applied Economics, 23(2), 147-168.

Fisher, I. (1933): The debt-deflation theory of great depressions, in: Economica, 1, 337-357.

Flaig, G., Rottmann, H. (2013): Labour market institutions and unemployment: an international panel data analysis, in: Empirica, 40, 635-654.

Hein, E., Vogel, L. (2008): Distribution and growth reconsidered - empirical results for six OECD countries, in: Cambridge Journal of Economics, 32, 479-511.

IMF (International Monetary Fund) (2003): Unemployment and labor market institutions: why reforms pay off, in: World Economic Outlook 2003, Washington, DC: IMF, ch. 4.

Kaldor, N. (1970): The new Monetarism, in: Lloyds Bank Review, 97, 1-18. 
Kaldor, N. (1982): The Scourge of Monetarism, Oxford: Oxford University Press.

Karanassou, M., Snower, D.J. (1998): How labour market flexibility affects unemployment: longterm implications of the chain reaction theory, in: Economic Journal, 108, 832-849.

Karanassou, M., Sala, H., Salvador, P.F. (2008): Capital accumulation and unemployment: new insights on the Nordic experience, in: Cambridge Journal of Economics, 32, 977-1001.

King, J. (2002): A History of Post Keynesian Economics since 1936, Cheltenham, UK and Northampton, MA: Edward Elgar.

Lavoie, M. (2003): Real wages and unemployment with effective and notional demand for labor, in: Review of Radical Political Economics, 35(2), 166-182.

Layard, R., Nickell, S., Jackman, R. (1991): Unemployment: Macroeconomic Performance and the Labour Market, Oxford: Oxford University Press.

León-Ledesma, M. (2002): Unemployment hysteresis in the US and the EU: a panel data approach, in: Bulletin of Economic Research, 54, 95-105.

Naastepad, C.W.M., Storm, S. (2007): OECD demand regimes (1960-2000), in: Journal of PostKeynesian Economics, 29(2), 213-248.

Nickell, S. (1998): Unemployment: questions and some answers, in: Economic Journal, 108, 802-816.

Nickell, S., Nunziata, L., Ochel, W. (2005): Unemployment in the OECD since the 1960s. What do we know? in: Economic Journal, 115, 1-27.

OECD (1994): OECD Jobs Study, Paris: OECD.

OECD (2006): OECD Employment Outlook, Paris: OECD.

OECD (2009): Beyond the crisis: medium-term challenges relating to potential output, unemployment and fiscal positions, in: OECD Economic Outlook 85, Paris: OECD, ch. 4.

OECD (2010): Return to work after the crisis, in: OECD Economic Outlook 87, Paris: OECD, ch. 5.

OECD (2011): Persistence of high unemployment: what risks? What policies? in: OECD Economic Outlook 89, Paris: OECD, ch. 5.

Onaran, Ö., Galanis, G. (2012): Is aggregate demand wage-led or profit-led? National and global effects, in: Conditions of Work and Employment Series, No. 40, International Labour Office.

Røed, K. (1997): Hysteresis in unemployment, in: Journal of Economic Surveys, 11(4), 389-418.

Rowthorn, R. (1977): Conflict, inflation and money, in: Cambridge Journal of Economics, 1(3), 215-239.

Rowthorn, R. (1995): Capital formation and unemployment, in: Oxford Review of Economic Policy, 11(1), 26-39.

Rowthorn, R. (1999): Unemployment, wage bargaining and capital-labour substitution, in: Cambridge Journal of Economics, 23, 413-425.

Skott, P. (2005): Fairness as a source of hysteresis in employment and relative wages, in: Journal of Economic Behavior and Organization, 57, 305-331.

Stanley, T. (2004): Does unemployment hysteresis falsify the natural rate hypothesis? A meta-regression analysis, in: Journal of Economic Surveys, 18(4), 589-612.

Stockhammer, E. (2004): Explaining European unemployment: testing the NAIRU hypothesis and a Keynesian approach, in: International Review of Applied Economics, 18(1), 3-24.

Stockhammer, E. (2008): Is the NAIRU a Monetarist, New Keynesian, Post Keynesian or Marxist theory? in: Metroeconomica, 59(4), 479-510.

Stockhammer, E. (2011): Wage norms, capital accumulation and unemployment: a Post Keynesian view, in: Oxford Review of Economic Policy, 27(2), 295-311.

Stockhammer, E., Klär, E. (2011): Capital accumulation and unemployment in the medium run, in: Cambridge Journal of Economics, 35, 437-457.

Stockhammer, E., Onaran, Ö., Ederer, S. (2009): Functional income distribution and aggregate demand in the Euro area, in: Cambridge Journal of Economics, 33(1), 139-159. 